\title{
De cero a dinero: La basura como fuente principal para un negocio inclusivo de reciclaje en Cuenca (Ecuador)
}

\section{From zero to cash: Waste as a main source for an inclusive recycling business in Cuenca (Ecuador)}

\begin{abstract}
Edisson Santiago Cajamarca Cajamarca es investigador de la Universidad de Cuenca (Ecuador) (santiago.cajamarca@ucuenca.edu.ec) (https://orcid.org/0000-0002-7196-8911

William Ramiro Bueno Sagbaicela es investigador de la Universidad de Cuenca (Ecuador) (william.bueno@ucuenca.edu.ec) (https://orcid.org/0000-0002-9115-6232
\end{abstract}

José Santiago Jimbo Días es profesor e investigador de la Universidad de Cuenca (Ecuador) (santiago.jimbo@ucuenca.edu.ec) (https://orcid.org/0000-0002-2823-4285)

\begin{abstract}
Resumen
El presente trabajo se enmarca en la relación existente entre el ingreso y la actividad del reciclaje bajo el contexto de Negocio Inclusivo (NI). Esta población de recicladores definida como pobre y vulnerable por la Base de la Pirámide Económica (BDP) en función de sus ingresos anuales, es el centro de la cadena de valor de reciclaje. Se plantea determinar si la figura de asociación de los recicladores influye directamente en su nivel de ingreso y evaluar las condiciones en las que se realiza la actividad del reciclaje para analizar la oportunidad de generar rentabilidad como NI para estos grupos vulnerables. La metodología empleada, con carácter cuantitativo-inductivo de corte transversal, se centrará en el estudio de 150 recicladores, 27 centros privados (intermediarios) y dos centros corporativos de reciclaje. En los resultados destaca el diseño de la cadena de valor de reciclaje para la ciudad de Cuenca (Ecuador), la débil correlación entre estar asociado y el nivel de ingreso del reciclador, así como el elevado margen bruto comercial de un intermediario. La conclusión principal demuestra que el reciclaje tiene bondades económicas atractivas para crear un NI y los intermediarios son los principales beneficiarios dentro de esta actividad. Los recicladores se ven limitados por sus condiciones de trabajo y la figura de asociación no se considera como una solución imperante para mejorar su nivel de ingreso.
\end{abstract}

\begin{abstract}
In an inclusive business (NI) context, this manuscript addresses the relationship between income and recycling. Within recycling, recycle workers are considered poor and vulnerable based on the economic pyramid (BDP) due to their annual income. Moreover, they depict the core of a value chain which includes various participants. On one hand, this research determines if the recyclers' association membership directly influences their income level. On the other hand, it sets out to evaluate recycling working conditions to reveal an opportunity to generate profitability as an inclusive business. The methodology applied in this research is a cross-sectional study that follows an inductive approach to analyze quantitative information focused on 150 recycle workers, 27 private centers (intermediaries) and 2 recycling corporative centers. The highlights of the results are the value chain design from the city of Cuenca (Ecuador), the high commercial gross margins from intermediaries and the ensuing weak correlation between recycler's association membership and income level. Hence, the overriding conclusions show that recycling has promising economic advantages conducive to create an inclusive business, considering that intermediaries are the main beneficiaries. Furthermore, recycle workers are limited because of their working conditions, and lastly the recycling association membership does not bring clear advantages regarding income level improvement.
\end{abstract}

\section{Palabras clave I keywords}

Ingreso, recicladores, cadena de valor, negocio inclusivo, residuos sólidos, Cuenca.

Income, recycle workers, value chain, inclusive business, solid waste, Cuenca.

Cómo citar: Cajamarca Cajamarca, E.S., Bueno Sagbaicela, W.R. y Jimbo Días, J.S. (2019). De cero a dinero: La basura como fuente principal para un negocio inclusivo de reciclaje en Cuenca (Ecuador). Retos Revista de Ciencias de la Administración y Economía, 9(17), 71-87. https://doi.org/10.17163/ret.n15.2018.05 


\section{Introducción y estado de la cuestión}

La presente investigación parte de la necesidad de integrar a la población de recicladores en la dinámica económica global a través del desarrollo de modelos de Negocio Inclusivo (NI), que son iniciativas empresariales que incorporan al segmento de la «Base de la Pirámide» (BDP) en su cadena de valor, contribuyendo a la reducción de la pobreza, generar mayor acceso a oportunidades y facilitar que estas comunidades sean generadoras de ingresos y ejerzan el derecho a la libertad económica (Ishikawa Lariú \& Strandberg, 2009), de tal forma que favorezca el alcance de ciertos Objetivos de Desarrollo Sostenible (ODS) tales como: fin a la pobreza, igualdad de género, reducción de las desigualdades, ciudades y comunidades sostenibles; y en específico el objetivo 12 que hace referencia a la producción y consumo responsable en el cual radica la importancia de reciclar y reducir los desechos, de acuerdo con el Programa de las Naciones Unidas para el Desarrollo (PNUD, 2016).

\subsection{Generación de basura y el reciclaje}

Los países desarrollados y en vías de desarrollo enfrentan un crecimiento poblacional y progreso industrial que se asocia a la producción de grandes cantidades de residuos sólidos (Akhtar et al., 2017; Oyekale, 2017; Yang et al., 2018) debido a que la sociedad de hoy explota diferentes materiales (Vázquez et al., 2016). Nuestras prácticas de consumo elevan las tasas de generación de residuos sólidos (Vieira \& Matheus, 2018) puesto que, según Ribeiro y Kruglianskas (2015), continúa predominando el modelo económico lineal de extraer, manufacturar, usar y descartar (citados por Wadhy et al., 2017).

Benton-Short y Short (2013) señalan que la generación de basura, junto con los problemas de recolección, disposición y los riesgos ambientales, continúan siendo un desafío para muchas ciudades (citados por Jiménez, 2015), más aún la gestión para los municipios que resulta una gran dificultad (Abdoli, Rezaei, \& Hasanian, 2016; Meylan et al., 2018; Botello et al., 2018). Esta gestión de los municipios continúa en desarrollo con pequeños proyectos piloto incluyendo al sector informal del reciclaje (Ferronato et al., 2018), considerando a otros trabajos públicos más importantes (Ross \& Rogoff, 2012). Significa entonces que es crucial el aumento de determinación de las autoridades locales para resolver dichos inconvenientes (Ferreira, Bila, \& Ritter, 2017).

A escala mundial, en 2010 se generaron un total de entre 7 a 10 millones de toneladas de residuos sólidos (Wilson \& Velis, 2015). Según el Global Waste Management Outlook (GWMO), se producen cerca de dos billones de toneladas de Residuos Sólidos Municipales (RSM) por año (citado por Byamba \& Ishikawa, 2017; Sorkun, 2018). Basta señalar que Kawai y Tasaki (2016) afirman que en las grandes metrópolis se pronostica una generación de 2.2 billones de toneladas para 2025 (citados por Gu et al., 2018). Los países desarrollados pertenecientes a la Organización para la Cooperación y el Desarrollo Económicos (OCDE) son catalogados como los países con mayor cantidad de residuos generados a nivel global, como el caso de Estados Unidos, México y gran parte de la Unión Europea, entre otros, que generan un 62\% de residuos, seguidos de Asia Oriental y el Pacífico con el 21\%. Por su parte, América 
Latina y El Caribe (ALC) generan un 12\% y el restante 5\%, África Subsahariana (Borrás, 2018).

Hoornweg y Bhada-Tata (2012) mencionan que el Banco Mundial proyecta una generación de 220 millones de toneladas de residuos sólidos urbanos para 2025 en ALC (citados por Hernández et al., 2016). Asimismo, en ALC se espera un incremento del 66\% en la generación de residuos (TN/día) en menos de diez años (Padilla \& Trujillo, 2018). En efecto, en ALC se producen alrededor de 0,63 kg/hab/día de residuos sólidos domiciliarios y $0,93 \mathrm{~kg} / \mathrm{hab} /$ día respecto a los residuos sólidos urbanos (Sanmartín, Zhigue, \& Alaña, 2017).

En base con lo mencionado, es primordial conocer el flujo de la cadena de valor del reciclaje, que la Iniciativa Regional para el Reciclaje Inclusivo (IRR, 2013) planteó: "inicia en el momento que los residuos son generados y finaliza con la venta de los materiales transformados a la industria nacional o su exportación a terceros países" (p.12). En la figura 1 se refleja el modelo simplificado de la cadena de valor propuesta que puede variar de acuerdo a la realidad de cada país dentro de ALC.

\section{Figura 1. Cadena de Valor de Reciclaje para América Latina y El Caribe}

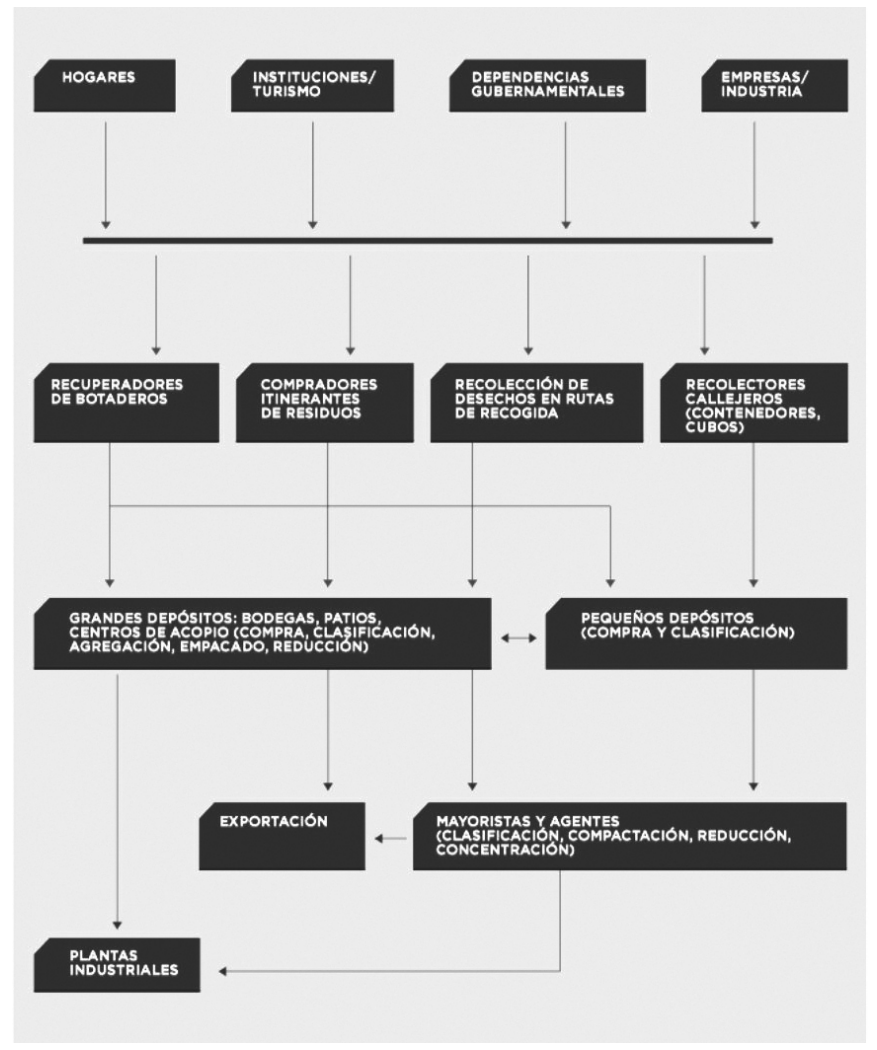

Fuente: Iniciativa Regional de Reciclaje Inclusivo (IRR, 2013, p. 12). 
Según la IRR (2013) esta «cadena de valor» del sector se compone por distintos actores que se agrupan de acuerdo a su forma de trabajo respecto a los residuos sólidos: los generadores son aquellos productores de los distintos residuos y desechos sólidos; la recolección es brindada por el servicio de recuperación de residuos sólidos urbanos y segregación de recicladores de base. El material recuperado se traslada a centros de acopio o intermediarios que acumulan y comercializan para que finalmente el material esté a disposición de plantas industriales o que se exporte en el caso de no existir mercado local (IRR, 2013).

Resulta oportuno definir el reciclaje y Castells (2012) lo describe como una operación que permite recuperar, transformar y elaborar un material a partir de residuos, además señala que "el reciclaje y los residuos, responden a diversas actividades que pueden llevarse a cabo sobre los diferentes flujos de residuos para aprovecharse, desde el mismo uso hasta otra aplicación" (citado por Álvarez, 2013, p. 11), reduciendo costos en el manejo de rellenos sanitarios, impactos por contaminación y problemas de salud (Sullivan Sealey \& Smith, 2014). Según Gray (2017), del World Economic Forum (WEF), Alemania es líder a nivel mundial con el $56,1 \%$ respecto a la tasa de reciclaje de RSM, tal y como se observa en la figura 2; Austria con un 53,8\%, Corea del Sur con 53,7\%, Gales con el $52,2 \%$ y el resto de países se ubican por debajo del $50 \%$.

Figura 2. Top 10 Tasa de Reciclaje de Residuos Sólidos Municipales 2017

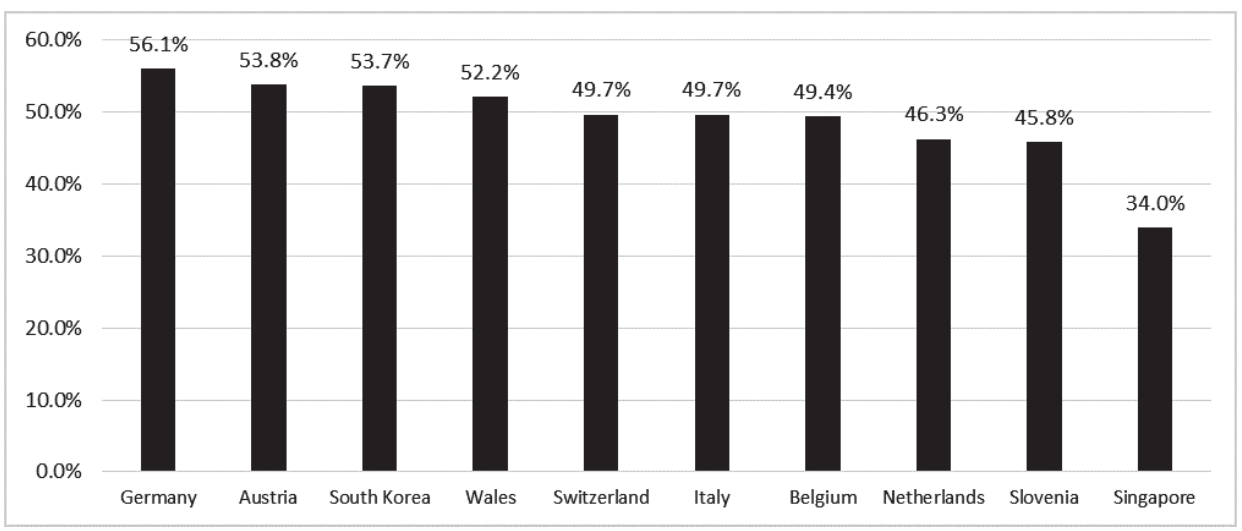

Fuente: World Economic Forum (WEF).

\subsection{Clasificación de residuos en Ecuador}

En Ecuador, según Bravo y Bravo (2012), el reciclaje inició con la implantación de una fábrica de papel por el año 1970, requiriendo material reciclado como principal materia prima para elaborar sus productos (citados por Silva et al., 2015). En 2017, el país recicló únicamente entre un 15 y 25\% del total de un millón de toneladas que podrían haberse recuperado (Alarcón, 2017).

En esa misma línea, a escala nacional, según el Instituto Nacional de Estadísticas y Censos (INEC, 2017) el 47,47\% de las familias ecuatorianas clasificó los residuos, un porcentaje superior a 2015 y 2016 con un 39,40\% y 41,46\% respecti- 
vamente. El plástico es el principal residuo más reciclado actualmente (32,98\%) superando a los residuos orgánicos e inorgánicos como papel, cartón y vidrio (INEC, 2017)

De acuerdo con la IRR (2017b) en 2014 se generaron 4'100.000 toneladas de residuos sólidos de los cuales 1'025.000 son residuos potencialmente reciclables y tan sólo el $24 \%$ de ese potencial fue recuperado y reciclado. El $51 \%$ de las 245.000 toneladas recicladas fueron recuperadas por recicladores de base en las principales ciudades del país. En 2017, la cantidad de hogares cuencanos que clasificaron los residuos fueron alrededor del 53,37\%, ubicándose por encima de Guayaquil, Quito, Machala y Ambato (INEC, 2017).

\subsection{Cuenca, una ciudad con potencial}

Partiendo de que los recicladores de base son personas con bajos recursos que "recolectan y clasifican residuos en las calles, vertederos a cielo abierto $\mathrm{u}$ otros puntos en la cadena de los RSM buscando materiales con potencial valor de reventa (...) tienden a pertenecer a los sectores más pobres y vulnerables de la sociedad" (The Economist Intelligence Unit, 2017, p. 7), no obstante se empleará la denominación de recicladores primarios (RP) propuesta por la Empresa Pública Municipal de Aseo de Cuenca (EMAC-EP, 2018). Es importante señalar que la condición de vulnerabilidad de esta población debe ser abordada desde una base de prioridades bien reconocidas para el bienestar humano que incluyen la seguridad alimentaria, los ingresos, agua y saneamiento, salud, educación, energía, igualdad de género, equidad social y puestos de trabajo (Velenturf \& Jopson, 2019).

Estas personas se enmarcan en el concepto de la «Base de la Pirámide»(BDP) desarrollada por Prahalad y Hart (2002) que dividen en niveles de acuerdo al ingreso anual per cápita basado en la Paridad de Poder Adquisitivo (PPA), usando el gráfico de una pirámide para representar los rangos de ingresos. En el nivel 4 -denominado BDP- "se encuentran 4 mil millones de personas cuyo ingreso es inferior a $\$ 1.500,00$ dólares al año” (Jimbo, 2016, p. 143).

Dadas las condiciones que anteceden, se evidencia que la idea de formar un NI entorno al reciclaje es factible, según los aportes de Licandro (2013), Prahalad y Hammond (2005), AVINA (2010); quienes consideran a los NI como estrategias empresariales que "buscan la rentabilidad económica bajo la perspectiva de lo social y ambiental, donde los primeros beneficiarios sean las personas en situación de pobreza y vulnerabilidad, siendo aliados estratégicos para su consecución las empresas y el estado" (citados por Jimbo \& Nauta, 2017, p. 102).

En ese mismo orden de ideas, en Cuenca existe el potencial para la creación de un NI de reciclaje. Esta afirmación se respalda en datos proporcionados por la EMAC-EP (2018) que asegura que, solo en 2017, la generación per cápita de desechos y residuos sólidos dentro del casco urbano fue $0,54 \mathrm{~kg} / \mathrm{hab} /$ día, ascendiendo a 9.288 TN/mes; de los cuales el 25,8\% es material inorgánico aprovechable y de este material se está recuperando sólo el 19,2\%. Por lo general, el material inorgánico es percibido con un valor monetario nulo, no así para los RP, puesto que se consideran un recurso, por el potencial para generar ganancias mediante su reciclaje (Giovannini \& Huybrechts, 2017) provocando que a escala global "15 millones de personas se encuentran involucradas en el reciclaje informal de residuos" (Yang, et al., 2016, p. 
452). Asimismo, la gestión eficiente de los recursos naturales compartidos y la forma en la que se eliminan los desechos tóxicos son el sustento vital para alcanzar el objetivo de producción y consumo responsable, para crear cadenas de producción y suministro más eficientes (PNUD, 2016).

\section{Materiales y método}

En este trabajo se plantea como hipótesis de partida que el nivel de ingreso de un reciclador primario (RP) no está en función de su condición de asociado. Se plantea, así, dar respuesta a los siguientes objetivos: i) Determinar la relación existente entre el ingreso y la forma de llevar a cabo su actividad: asociados vs no asociados; ii) Evaluar las condiciones en las que se realiza la actividad de reciclaje en Cuenca (Ecuador) y; iii) Analizar si existe la oportunidad de generar rentabilidad en el reciclaje bajo el contexto de NI.

La presente es una investigación de diseño cuantitativo, con enfoque inductivo y de corte transversal, articulada como un trabajo de campo. Para determinar la muestra se empleó la fórmula propuesta por Murray y Larry (2009) que se aplica a poblaciones finitas: con un nivel de confianza del 95\% y un margen de error muestral de $+/-5 \%$, el resultado obtenido fue un total de 150 observaciones. Según el registro oficial de la EMAC-EP, a julio de 2018 se registraban un total de 246 RP en Cuenca, a quienes se consideró como población para la obtención de la muestra.

Se llevó a cabo la aplicación de encuestas a los 150 RP en convocatorias realizadas por la EMAC-EP, con la finalidad de obtener datos referentes a la actividad de reciclaje. De la misma forma se realizaron visitas técnicas a los dos únicos centros corporativos de reciclaje con el objetivo de obtener información concerniente a la gestión del material recuperado y adicionalmente, como medida de validación y control, se pidió el llenado de formularios de información a 27 centros privados de reciclaje (intermediarios) identificados en la ciudad.

El diseño y estructuración de las encuestas y formularios están basados en instrumentos empleados en investigaciones de la IRR (2017a) que se ajustaron para dar cumplimiento a los objetivos de la presente investigación. En el caso de los RP, la encuesta constó de 25 preguntas categorizadas en las siguientes dimensiones: i) Datos generales; ii) Nivel educativo y; iii) Condiciones y características de la actividad del reciclaje. Para los intermediarios, los formularios constaron de 14 preguntas. Si un intermediario no ofrece información es excluido por no ofrecer datos de interés. Asimismo, se categorizaron en dos dimensiones: Datos generales y Actividad económica.

El registro, tabulación y tratamiento de los datos obtenidos se realizaron mediante la herramienta estadística de Excel para la generación de información. Para establecer el grado de representatividad entre las variables de ingreso y asociación, se empleó una prueba de hipótesis, análisis de correlación y análisis de varianzas (ANOVA). Este último probó que las medias de dos o más poblaciones son iguales, en este caso, comparando las variaciones de los ingresos medios de los recicladores que se encuentran asociados vs los no asociados. Adicionalmente, se consideró necesario exteriorizar el grado de antagonismo que presenta el ingreso de un intermediario en comparación con el percibido por un RP, exponiendo el margen bruto comercial por material comercializado. Esto 
enmarcado en las realidades variadas que presenta la actividad del reciclaje en cada uno de los niveles que posee la cadena de valor del reciclaje.

\section{Análisis y resultados}

\subsection{Cadena de valor del reciclaje en Cuenca, los recicladores primarios como una pieza fundamental}

Los criterios tanto de Porter (1986) como de Francés (2001), sirven para conceptualizar la cadena de valor como una herramienta de análisis que permite identificar formas de generar valor radicando en hacer el mayor esfuerzo en lograr la fluidez de los procesos productivos (citados por Quintero \& Sánchez, 2006). Dicho esto, junto con la observación realizada y la información brindada por la EMAC-EP, en la figura 3 se visualiza la cadena de valor diseñada para Cuenca.

Figura 3. Cadena de Valor de Reciclaje de Cuenca

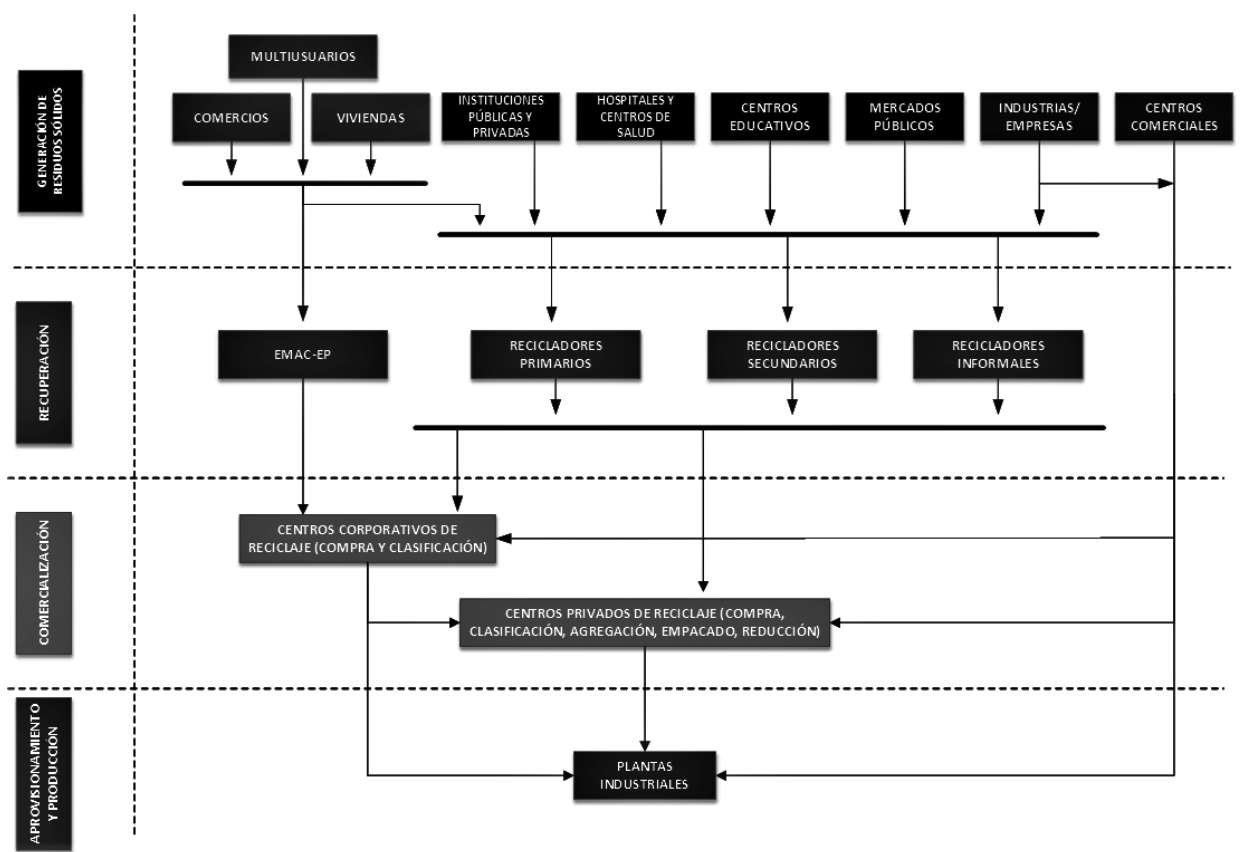

Atendiendo a la figura que precede, los generadores son los productores de desechos y residuos sólidos que es la ciudadanía en general. Según la EMAC-EP (2018), Cuenca cuenta con una población de 591.996 habitantes con 565.476 pertenecientes a la parte urbana por lo que es necesaria su convicción para una separación correcta de dichos residuos (De Feo et al., 2018).

En la segunda fase, la de recuperación, intervienen la EMAC-EP y recicladores primarios (RP), secundarios e informales. La empresa pública traslada el material 
sólo de un segmento de los generadores. Los RP están autorizados por la EMAC-EP que realizan la recolección de forma artesanal empleando medios de transporte no motorizados a diferencia de los secundarios que poseen un vehículo motorizado para el traslado del material recuperado. Finalmente figuran los recicladores informales, de quienes la EMAC-EP no posee un registro y que reciclan sin autorización alguna.

Se visualizan dos tipos de centros de acopio: el primero denominado "Centros Corporativos de Reciclaje» (CCR), administrados por asociaciones de RP que recuperan, clasifican y comercializan el material. El segundo tipo son los «Centros Privados de Reciclaje» (CPR), comúnmente reconocidos como intermediarios y que ejecutan labores adicionales a los CCR, como el embalaje y/o transformación.

El proceso culmina con las industrias que se abastecen del material reciclado como materia prima para su producción, siendo el caso de Acería del Ecuador C.A. Adelca y Cartopel las únicas empresas en Cuenca. La chatarra, bronce, cobre, aluminio, papel, cartón y dúplex son requeridos por el mercado local, mientras que el resto de materiales se comercializan fuera del cantón, enviándose a ciudades como Guayaquil y Quito.

Como se visualiza en la figura 3 , los RP son fundamentales en la cadena de valor y es relevante exponer las condiciones bajo las cuales ellos realizan la actividad. Al conformarse por un 76,7\% de mujeres y $23,3 \%$ de hombres, se respalda lo que la International Labour Office (ILO) alega sobre la mayor participación de mujeres en el empleo informal (citado por Ogando, Roever, \& Rogan, 2017) quienes han encontrado en el reciclaje una oportunidad laboral. Su edad promedio bordea los 45 años, registrándose una edad mínima de 19 y máxima de 77 años. El 75,7\% de la muestra de género femenino recibió educación primaria o secundaria y el restante $24,3 \%$ nunca asistió a centros educativos formales. Por su parte, el 88,6\% de varones tuvieron formación académica y sólo el 11,4\% no recibió instrucción alguna.

Esta actividad la han efectuado por alrededor de 12 años en promedio, donde el 77,0\% de RP trabajan en las calles recorriendo el centro histórico, principales avenidas, ciudadelas, parques, mercados y el parque industrial. Los centros de acopio acaparan un 10,9\% de recicladores; el 7,5\% recuperan en instituciones y edificios; el 4,6\% trabajan en otros lugares de la ciudad. El 53,3\% de los recicladores prefieren trabajar solos y $46.3 \%$ lo realizan en promedio en grupos de tres personas, comúnmente conformados por los cónyuges o miembros de su círculo familiar para que los ingresos percibidos al momento de la venta del material sean distribuidos entre los miembros de una misma familia y proteger su ruta de recuperación de material por problemas de organización e invasión de territorios.

Existen meses donde se observa mayor cantidad de material. En el periodo julio-agosto-septiembre, gran número de hogares desechan material escolar del año lectivo anterior. El segundo periodo diciembre-enero coincide con Navidad y Año Nuevo. Un 14,50\% de RP no consideran una oportunidad el incremento de material en dichos meses, puesto que también acrecienta la cantidad de recicladores informales. 


\subsection{Ingreso de los recicladores, el valor real de la "basura» y la figura de asociación}

En Cuenca existen 16 materiales identificados por la EMAC-EP con un valor económico y que son posiblemente recuperables enlistados en la tabla 1. Es fundamental aclarar que se da prioridad a ciertos materiales al momento de la recuperación en función de los requerimientos de CPR, CCR e industria.

Tabla 1. Precios promedio por material

\begin{tabular}{|l|c|}
\hline \multicolumn{1}{|c|}{ Material } & Precio promedio ( US\$/kg) \\
\hline Cartón & 0,09 \\
\hline Dúplex & 0,09 \\
\hline Periódico & 0,07 \\
\hline Mixto & 0,09 \\
\hline Papel Blanco & 0,13 \\
\hline Plástico Suave & 0,16 \\
\hline Soplado & 0,12 \\
\hline PET & 0,45 \\
\hline Chatarra & 0,13 \\
\hline Tetra pack & 0,10 \\
\hline Vidrio & 0,02 \\
\hline Aluminio & 0,33 \\
\hline Cobre & 1,59 \\
\hline Bronce & 1,21 \\
\hline Chatarra Electrónica (RAEE) & 0,54 \\
\hline Otros & 0,03 \\
\hline
\end{tabular}

Se estima una recuperación total de 129,68 TN/mes por los RP siendo los materiales más recuperados el cartón con un 32,1\% seguido por papel blanco con un $10,6 \%$, vidrio con $10,2 \%$, chatarra con $8,6 \%$, plástico suave con $7,7 \%$, PET (envases hechos con tereftalato de polietileno) con 7,6\% y el soplado con $6,8 \%$. Otros materiales no se recuperan en gran cantidad por razones de demanda del mercado, logística, adecuada clasificación y precios no representativos. A pesar de que el PET es un material que no se dispone en grandes cantidades, posee un precio prominente.

El ingreso mensual de un reciclador está en función del volumen y precio de mercado del material como se puede apreciar en la figura 4. Un 52,7\% de RP percibieron un ingreso inferior a US $\$ 100,00$ mensuales; $22,0 \%$ entre US $\$ 100,00$ y US $\$ 150,00$; $16,0 \%$ entre US $\$ 150,00$ y US $\$ 200,00$; finalmente el 9,30\% recibió un ingreso superior a US $\$ 200,00$ por concepto de reciclaje. En promedio el ingreso mensual de un reciclador es US $\$ 76,16$ empleando aproximadamente 4,19 días/semana durante 5,50 horas/ 
día. Significa que trabajan alrededor de 92,11 horas/mes llegando a recuperar cerca de 527,16 kilogramos de material. Es importante aclarar en este punto que el salario mínimo mensual en Ecuador es de US\$394,00.

Figura 4. Ingreso Promedio Mensual por Material

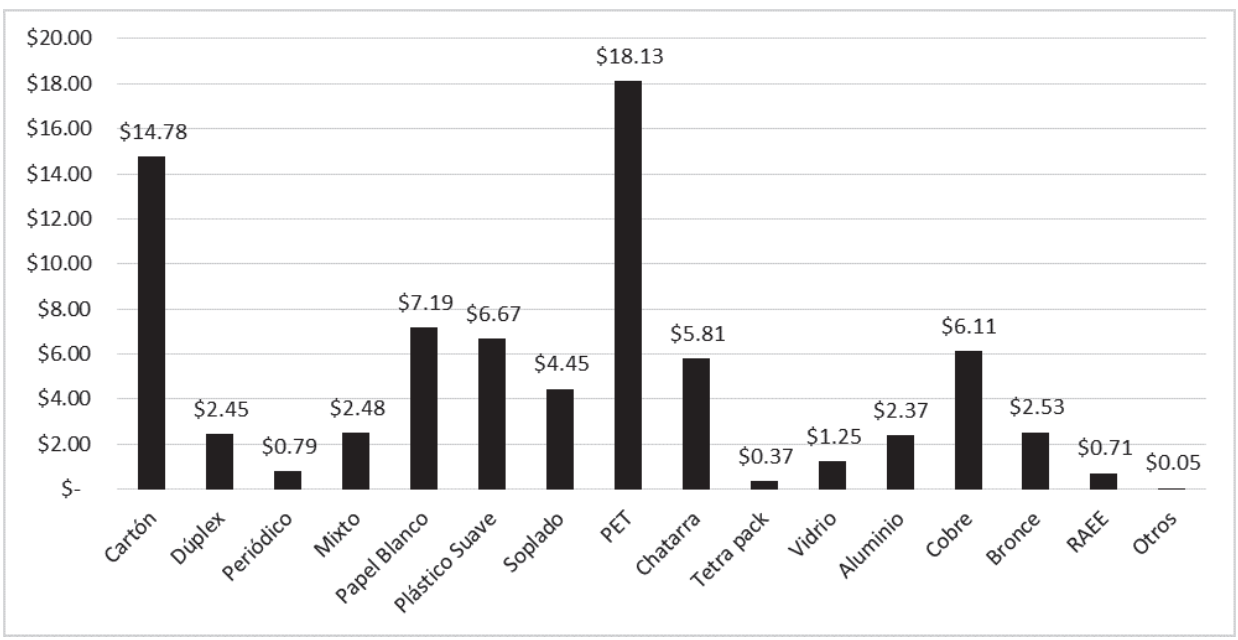

Para el 33,0\% de los RP resultan insuficientes los ingresos percibidos en el reciclaje, lo que les obliga a trabajar adicionalmente en comercios informales, limpieza, trabajo doméstico y actividades agrícolas. La figura de asociación nace justamente como una alternativa para superar los bajos ingresos. Existen siete asociaciones registradas en la EMAC-EP: Corporación ARUC, Corporación AREV, Asociación Solidaria del Sur Feria Libre, Asociación San Alfonso-Centro Histórico, Organización Pichacay, Asociación El Chorro y Asociación Cristo Rey. Tienen dificultades respecto a organización, registro de nuevos socios, falta de infraestructura, reuniones itinerantes y conflicto de intereses, existiendo sólo un 41,3\% de recicladores en condición de asociados (RA) y por ende un 58,7\% de recicladores no asociados (RNA), quienes no asumen a la asociación como una ventaja ni una prioridad por mala percepción, falta de conocimiento y poca disponibilidad de tiempo para cumplir con obligaciones de los asociados.

Existe una diferencia poco significativa referente al ingreso entre RA y RNA: los primeros perciben un ingreso promedio mensual de US\$80,85 y los RNA de US $\$ 70,90$, revelando que el RA consigue un 14,0\% más de ingreso, incluso el 14,5\% de RA han superado los US $\$ 200,00$ y sólo un escaso 5,7\% de RNA alcanzaron superar esa cifra. Esta diferencia se puede atribuir a la jornada laboral, puesto que los RA trabajan en promedio 114,07 horas/mes, en contraposición con las 78,00 horas/mes laboradas por los RNA.

Una vez determinado el ingreso de los RP, se realizó un análisis de correlación para determinar el nivel de dependencia respecto a la variable «asociación». Se obtuvo un coeficiente de correlación (r) de $0,68 \%$ como se observa en la tabla 2 , lo cual 
implica que existe una relación positiva pero insignificante estadísticamente, es decir, la asociación no es una variable explicativa e influyente en el nivel de ingreso. Esto se debe a que cinco de las siete asociaciones existentes se limitan a ámbitos organizacionales y registrar nuevos socios, pasando por alto el tema productivo.

Tabla 2. Estadísticos de relación

\begin{tabular}{|l|c|}
\multicolumn{1}{|c|}{ Estadístico } & Valor \\
\hline Coeficiente de correlación $\mathrm{r}$ & 0.116224714 \\
\hline Coeficiente de determinación $R^{2}$ & 0.013508184 \\
\hline$R^{2}$ ajustado & 0.006842699 \\
\hline Valor p (dos colas) & 0.173596059 \\
\hline Alfa & 0.05 \\
\hline
\end{tabular}

Dado el valor p del estadístico F calculado en la tabla 3, y el nivel de significación del $+/-5 \%$, la información que aportan las variables explicativas no es significativamente mejor que la que proporcionaría una media básica, es decir, las diferencias de las medias de los ingresos entre los RA y RNA no son significativas, aceptándose la hipótesis de que el nivel de ingreso de un RP no está en función de su condición de asociado.

Tabla 3. Análisis de Varianzas: ANOVA

\begin{tabular}{|l|c|c|c|c|c|}
\cline { 2 - 6 } \multicolumn{1}{c|}{} & DF & $\begin{array}{c}\text { Suma de } \\
\text { cuadrados }\end{array}$ & Media cuadrática & F & Pr > F \\
\hline Modelo & 1 & 5411.660 & 5411.660 & 2.027 & 0.157 \\
\hline Error & 148 & 395209.173 & 2670.332 & & \\
\hline Total ajustado & 149 & 400620.833 & & & \\
\hline
\end{tabular}

En el caso de la corporación ARUC y la asociación El Chorro, se origina la figura de CCR, contando con la infraestructura mínima requerida para la clasificación y comercialización del material recuperado. Representan un medio de protección y desarrollo social y económico, debido a las condiciones cambiantes del mercado como fluctuaciones de precios y volúmenes, incremento de recicladores informales e inseguridad laboral. La principal ventaja radica en el poder de negociación del que disponen al momento de comercializar el material, exigiendo precios superiores por las cantidades considerables que poseen, pues las empresas que compran el material prefieren proveedores con capacidades de abastecimiento acorde a sus ciclos de producción.

\subsection{El negocio está en el volumen, el reto para el NI del reciclaje}

Conjuntamente con la EMAC-EP se identificaron $27 \mathrm{CPR}$, recalcando que existió un grado de resistencia para otorgar información de carácter privado y al momento no existe ninguna ordenanza o marco jurídico que regule totalmente su actividad económica. 
Hecha la explicación anterior, un intermediario emplea en promedio siete trabajadores en la planta con una jornada laboral de 42,99 horas/semana. Los materiales reciclables que comercializan provienen de varias fuentes: recicladores, CCR, oficinas y centros comerciales, unidades educativas e industrias. El CPR se abastece de forma diaria, semanal, quincenal y mensual, permitiendo que las operaciones de acopio, clasificación y embalaje se desarrollen de forma continua. La cartera de materiales reciclables que oferta un CPR es variada operando un estimado de 116,84 $\mathrm{TN} / \mathrm{mes}$ que les permite obtener un atractivo margen comercial bruto, evidenciado en la tabla 4.

Tabla 4. Margen bruto comercial para el intermediario por tipo de material

\begin{tabular}{|l|c|c|c|c|}
\hline \multicolumn{1}{|c|}{ Material } & $\begin{array}{c}\text { Precio de } \\
\text { venta (US\$/ } \\
\mathbf{k g})\end{array}$ & $\begin{array}{c}\text { Precio de } \\
\text { compra (US\$/ } \\
\text { kg) }\end{array}$ & $\begin{array}{c}\text { Diferencia } \\
\text { (US\$) }\end{array}$ & $\begin{array}{c}\text { Margen } \\
\text { Bruto }\end{array}$ \\
\hline Cartón & 0,13 & 0,09 & 0,05 & $34,8 \%$ \\
\hline Dúplex & 0,09 & 0,09 & 0,00 & $5,2 \%$ \\
\hline Periódico & 0,08 & 0,07 & 0,01 & $9,9 \%$ \\
\hline Mixto & 0,17 & 0,09 & 0,08 & $44,4 \%$ \\
\hline Papel blanco & 0,17 & 0,13 & 0,04 & $22,0 \%$ \\
\hline Plástico suave & 0,35 & 0,16 & 0,19 & $53,3 \%$ \\
\hline Soplado & 0,27 & 0,12 & 0,15 & $54,1 \%$ \\
\hline PET & 0,61 & 0,45 & 0,15 & $25,4 \%$ \\
\hline Chatarra & 0,18 & 0,13 & 0,06 & $30,2 \%$ \\
\hline Tetra pack* & - & 0,10 & - & - \\
\hline Vidrio & 0,03 & 0,02 & 0,01 & $22,7 \%$ \\
\hline Aluminio & 0,66 & 0,33 & 0,33 & $49,5 \%$ \\
\hline Cobre & 3,85 & 1,59 & 2,26 & $58,7 \%$ \\
\hline Bronce & 3,30 & 1,21 & 2,09 & $63,4 \%$ \\
\hline RAEE* & - & 0,54 & - & - \\
\hline Otros* & - & 0,03 & - & - \\
\hline
\end{tabular}

* Información no proporcionada por CPR (intermediarios).

El ingreso bruto mensual de un intermediario se estima que asciende a US\$ 25.346,73. Es importante mencionar que las actividades de un intermediario no aportan un valor agregado considerable, es decir, acumulan grandes volúmenes de material y lo comercializan. Casos puntuales de CPR realizan procedimientos adicio- 
nales, como el peletizado del plástico generando material reciclado (pellets) listo para su transformación en producto terminado. No obstante, los resultados que obtienen pueden ser una retribución a la iniciativa de emprendimiento y al riesgo asumido al realizar una inversión en este negocio enmarcado en un ambiente de informalidad e inestabilidad.

Como ya se ha aclarado, un NI plantea estrategias que favorezcan a la población pobre y vulnerable enmarcada en la BDP, cumpliendo los RP con este criterio. Consecuentemente, al reciclaje se lo puede divisar como un NI debido a que lo efectúan personas de la BDP "articulados con la empresa privada y con el apoyo de la generación de leyes u ordenanzas emitidas por el Estado Ecuatoriano y Gobiernos Autónomos Descentralizados Municipales (GADM), que permiten a esta población tener recursos económicos" (Jimbo, 2016, p. 152).

En esa misma línea, en Ecuador la empresa Novacero S.A., dedicada a producir materiales de acero para la construcción, ejemplifica el concepto de NI al trabajar conjuntamente con recicladores de chatarra y calificarlos como la base de sus operaciones, siendo abastecedores de la materia prima para sus procesos productivos. En 2008 se unió al programa de NI: «Ganamos Todos», donde brindó capacitación técnica y capital de trabajo a los recicladores interesados (Maldonado, 2012). Colaboraron inicialmente siete microempresarios. Más adelante el número ascendió a 27, para finalmente llegar a trabajar en 2012 con 200 recicladores que obtuvieron no menos de 260,00 US $\$$ /tonelada de chatarra al optimizar su productividad y conseguir mejores precios (Maldonado, 2012).

Sin duda la experiencia de Novacero refuerza la oportunidad de formar un NI en función de la BDP puesto que el precio por kilogramo de chatarra obtenido en el programa fue de US $\$ 0,26$; mayor a los US $\$ 0,13$ que recibe un reciclador en promedio, esto en gran medida es porque se elude la figura del intermediario en la cadena de valor al negociar directamente y en gran escala con la industria.

Precisando de una vez, el potencial del NI de reciclaje en Cuenca radica en el volumen del material reciclable, puesto que según la EMAC-EP (2018) apenas se está recuperando un $19,2 \%$ de las 2.396 toneladas métricas reciclables. Considerando el papel importante que juega la fluctuación de los precios de cada material respecto al volumen recuperado, los ingresos son sustanciales.

\section{Discusión y conclusiones}

La cadena de valor es una herramienta necesaria y útil para la evaluación del proceso que atraviesa todo producto o servicio y, debido a su inexistencia al momento de desarrollar el presente trabajo, ha sido fundamental elaborar su diseño ajustado a la realidad de Cuenca (Ecuador), no solo para entender el flujo del proceso de los residuos sólidos generados, sino también para el planteamiento de estrategias vinculadas a la aplicación del NI con las personas de la BDP. Además, es importante señalar que la cadena de valor diseñada y presentada en la figura 3, cuenta con la aprobación del departamento técnico de la EMAC-EP.

Por otra parte, se comprobó que bajo la figura de asociación, los RP obtienen un poco más en ingresos que los RNA. A pesar de ello, no son altamente representati- 
vos y como se demostró, la situación de asociación de RP no es una variable explicativa total e influyente en el nivel de ingreso. De todas formas, asociado o no, continúan formando parte de la BDP. En ese mismo sentido, se pudo constatar que las condiciones de trabajo de los RP no son propicias ni adecuadas, debido a la inestabilidad laboral, bajos ingresos, condiciones insalubres de trabajo, informalidad y conflictos de intereses. Es fundamental considerar la relación antagónica que posee la actividad del reciclaje, haciendo referencia a la edad promedio que posee un reciclador con la presencia mayoritaria del género femenino respecto al nivel de esfuerzo físico que se requiere para el desarrollo de la actividad.

Comprendiendo las condiciones en las que se desempeña la labor del reciclaje y una vez comprobado que el ingreso de un RA es levemente superior al RNA, no se puede considerar a la asociación como una solución dada las condiciones que anteceden. Requieren la inclusión de formalidad respecto a su constitución legal, estructura organizacional, procedimientos y responsabilidades debidamente definidos encaminados a mejorar su productividad y en consecuencia las condiciones socio-económicas.

De esta forma, dado el diseño de la cadena de valor de reciclaje para Cuenca, las medidas que EMAC-EP pueda tomar para mejorar la gestión de residuos sólidos, debe encaminarse a contribuir con los ODS (PNUD, 2016), lo cual representa un gran desafío y un llamado imperioso en busca de brindar mejores oportunidades para los recicladores en dicha gestión, no sólo por las malas prácticas de consumo de los ciudadanos (Vieira \& Matheus, 2018) y el modelo económico lineal (Ribeiro \& Kruglianskas, 2015) sino también por los problemas detectados en las asociaciones y las condiciones de trabajo de los recicladores, en particular por su condición etaria y la feminización de la actividad.

Finalmente, quienes al instante se están beneficiando económicamente del reciclaje son la industria al obtener materia prima más barata y los intermediarios que tienen ingresos muy superiores a los de un RP; justificado con la infraestructura, logística y capacidad de inversión para el tratamiento del material reciclado, concluyendo de esta manera que existe una rentabilidad atractiva entorno a la actividad, por lo tanto se demuestra que existe la oportunidad de generar rentabilidad en el reciclaje para los RP. Para el éxito de aplicar un NI de reciclaje rentable en Cuenca que repercuta en el ingreso del RP dependerá de factores como el planteamiento de una estrategia de negocio definida, alianzas estratégicas con la industria, los reglamentos $\mathrm{u}$ ordenanzas municipales que regulen eficiente y eficazmente la gestión de los residuos en la ciudad en toda la cadena de valor del reciclaje; la colaboración conjunta entre los organismos de control y los mismos recicladores; para finalizar, un modelo de gestión de CCR que se ajuste a la realidad descrita entorno a los RP.

\section{Referencias}

Abdoli, M., Rezaei, M., \& Hasanian, H. (2016). Integrated solid waste management in megacities. Global Journal of Environmental Science and Management, 2(3), 289-298. https://doi.org/10.7508/ gjesm.2016.03.008

Akhtar, S., Ahmad, A., Qureshi, M., \& Shahraz, S. (2017). Households willingness to pay for improved solid waste management. Global Journal of Environmental Science and Management, 3(2), 143-152. https://doi.org/10.22034/gjesm.2017.03.02.003 
Alarcón, I. (28 de Abril de 2017). Ecuador tiene un déficit en reciclar basura. El Comercio. (https:// bit.ly/2oo59TF) (2018-06-16).

Álvarez Gómez de Cos, C. M. (Diciembre de 2013). Reciclaje y su aporte a la educación ambiental (tesis de pregrado). Universidad Rafael Landívar, Quetzaltenango, Guatemala.

AVINA. (2010). Negocios y mercados inclusivos. Definición y marco conceptual para el trabajo de AVINA. Recuperado de ESADE: (https://bit.ly/2N1ppaQ) (2019-02-08).

Benton-Short, L., \& Short, B. (2013). Cities and Nature. London: Routledge.

Borrás, C. (2018). ¿Cuánto se recicla en el mundo? Recuperado de Ecología Verde: (https://bit.ly/2Fjvrlh) (2018-07-03).

Botello Álvarez, J. E., Rivas García, P., Fausto Castro, L., Estrada Baltazar, A., \& Gomez Gonzalez, R. (2018). Informal collection, recycling and export of valuable waste as transcendent factor in the municipal solid waste manegement: A Latin-American reality. Journal of Cleaner Production, 182, 485-495. https://doi.org/10.1016/j.jclepro.2018.02.065

Bravo, M., \& Bravo, B. (2012). Recynter: Una escuela de reciclaje y oportunidades. Revista Verde, 24, 8-10.

Byamba, B., \& Ishikawa, M. (2017). Municipal solid waste management in Ulaanbaatar, Mongolia: Systems Analysis. Sustainability, 9(6), 896. https://doi.org/10.3390/su9060896

Castells, X. E. (2012). Reciclaje de residuos industriales. Residuos sólidos urbanos y fangos de depuradora (Segunda ed.). Madrid: Díaz de Santos.

De Feo, G., Ferrara, C., Iannone, V., \& Parente, P. (2018). Improving the efficacy of municipal solid waste collection with a communicative approach based on easily understandable indicators. Science of the Total Environment, 651, 2380-2390. https://doi.org/10.1016/j.scitotenv.2018.10.161

Empresa Pública Municipal de Aseo de Cuenca (EMAC-EP). (2018). Autores que intervienen actualmente en el servicio de reciclaje. Cuenca.

Ferreira, J. A., Bila, D. M., \& Ritter, E. (2017). Solid waste management in small municipalities: the case history of Piraí (RJ), Brazil. International Journal of Environment and Waste Management, 19(2), 135-147. https://doi.org/10.1504/IJEWM.2017.083969

Ferronato, N., Gorritty Portillo, M. A., Guisbert Lizarazu, E. G., Torretta, V., Bezzi, M., \& Ragazzi, M. (2018). The municipal solid waste management of La Paz (Bolivia): Challenges and opportunities for a sustainable development. Waste Management and Research, 36(3), 288-299. https://doi.org/10.1177/0734242X18755893

Francés, A. (2001). Estrategia para la empresa en América Latina. Caracas: Ediciones IESA.

Giovannini, M., \& Huybrechts, B. (2017). How inclusive is inclusive recycling? Recyclers' perspectives on a cross-sector partnership in Santiago de Chile. Local Environment, 22(12), 1497-1509. https://doi.org/10.1080/13549839.2017.1363727

Gray, A. (2017). Germany recycles more than any other country. Recuperado de World Economic Forum: (https://bit.ly/2ACpeOh) (2018-06-04).

Gu, B., Li, Y., Jin, D., Yi, S., Gu, A., Bu, X., . . . Jia, R. (2018). Quantizing, recognizing, and characterizing the recycling potential of recyclable waste in China: A field tracking study of Suzhou. Journal of Cleaner Production, 201, 948-957. https://doi.org/10.1016/j.jclepro.2018.08.085

Hernández Berriel, M., Aguilar Virgen, Q., Taboada González, P., Lima Morra, R., Eljaiek Urzola, M., Márquez Benavides, L., \& Buenrostro Delgado, O. (2016). Generation and composition of urban solid waste in Latin America and the Caribbean. Revista Internacional de Contaminacion Ambiental, 32(1), 11-22. https://doi.org/10.20937/RICA.2016.32.05.02

Hoornweg, D., \& Bhada-Tata, P. (2012). What a waste. A global review of solid waste management. No. 15. Recuperado de World Bank: (https://bit.ly/2rI6nNn) (2019-02-08).

Iniciativa Regional para el Reciclaje Inclusivo (IRR). (2013). Caracterización del sector informal del reciclaje en América Latina y el Caribe. Recuperado de Reciclaje Inclusivo: (https://bit.ly/2VEJqYo) (2018-06-10). 
Iniciativa Regional para el Reciclaje Inclusivo (IRR). (2017a). Consultoría. Diseño de Planes de Inclusión Social para la Gestión de Reciclaje Inclusivo en 9 municipios seleccionados. Producto 5: Plan de Reciclaje Inclusivo de Cuenca. Cuenca, EMAC-EP.

Iniciativa Regional para el Reciclaje Inclusivo (IRR). (2017b). Avances en el reciclaje y en la inclusión de recicladores de base en el Ecuador. Recuperado de Reciclaje Inclusivo: (https://bit.ly/2CXQMPw) (2018-06-10).

Instituto Nacional de Estadísticas y Censos (INEC). (2017). Información ambiental en hogares-ENEMDU 2017. Recuperado de Ecuador en Cifras: (https://bit.ly/2TCAhh9) (2018-06-12).

Ishikawa Lariú, A., \& Strandberg, L. (2009). Cuaderno N5, Negocios Inclusivos: creando valor para las empresas y para la población de bajos ingresos. Recuperado de IESE Business School Universidad de Navarra: (https://bit.ly/2CX93fX) (2018-06-12).

Jimbo Días, J. S. (2016). El negocio inclusivo de reciclaje entendido como una estrategia empresarial a desarrollar por la industria manufacturera de papel y cartón en la ciudad de Cuenca-Ecuador. Economía y Política(24), 141-160. https://doi.org/10.25097/rep.n24.2016.06

Jimbo Días, J. S., \& Nauta Díaz, J. F. (2017). La persona como eje principal del negocio inclusivo de reciclaje: una revisión de literatura. Maskana, 101-110. (https://bit.ly/2ReB6A9) (2018-06-05).

Jiménez Martínez, N. M. (2015). La gestión integral de residuos sólidos urbanos en México: entre la intención y la realidad. Letras Verdes. Revista Latinoamericana de Estudios Socioambientales(17), 29-56. https://doi.org/10.17141/letrasverdes.17.2015.1419

Kawai, K., \& Tasaki, T. (2016). Revisiting estimates of municipal solid waste generation per capita and their reliability. Journal of Material Cycles and Waste Management, 18(1), 1-13. doi:https://doi.org/10.1007/s10163-015-0355-1

Licandro, O. (2013). El rol de las alianzas intersectoriales en la creación de negocios inclusivos con la base de la pirámide. Un análisis de la experiencia uruguaya mediante el estudio de casos. Recuperado de La sociedad civil: (https://bit.ly/2Bpg9Zm) (2019-02-08).

Maldonado, L. (2006). Reducción y reciclaje de residuos sólidos urbanos en centros de educación superior: Estudio de caso. Ingeniería, 10(1), 59-68. (https://bit.ly/2CZcJOb) (2018-06-06).

Maldonado, P. (2012). Grandes y pequeños ganan con el negocio inclusivo. Recuperado de Revista Líderes: (https://bit.ly/2TE9fpY) (2018-06-10).

Meylan, G., Lai, A., Hensley, J., Stauffacher, M., \& Krütli, P. (2018). Solid waste management of small island developing states-the case of the Seychelles: a systemic and collaborative study of Swiss and Seychellois students to support policy. Environmental Science and Pollution Research, 1-14. https://doi.org/10.1007/s11356-018-2139-3

Murray R., S., \& Larry J., S. (2009). Estadística (Cuarta ed.). México: McGraw-Hill.

Ogando, A. C., Roever, S., \& Rogan, M. (2017). Gender and informal livelihoods: Coping strategies and perceptions of waste pickers in Sub-Saharan Africa and Latin America. International Journal of Sociology and Social Policy, 37(7-8), 435-451. https://oi.org/10.1108/ IJSSP-06-2016-0077

Oyekale, A. S. (2018). Determinants of households' involvement in waste separation and collection for recycling in South Africa. Environment, Development and Sustainability, 20(5), 23432371. https://doi.org/10.1007/s10668-017-9993-x

Padilla, A., \& Trujillo, J. (2018). Waste disposal and households' heterogeneity. Identifying factors shaping attitudes towards source-separated recycling in Bogotá, Colombia. Waste Management, 74, 16-33. https://doi.org/10.1016/j.wasman.2017.11.052

Porter, M. (1986). Ventaja Competitiva. México: Editorial C.E.C.S.A.

Prahalad, C., \& Hammond, A. (2005). Atender a los pobres del mundo, rentablemente. Harvard Business Review, 83(8), 87-99. (https://bit.ly/2URMlf5) (2019-02-08).

Prahalad, C., \& Hart, S. L. (2002). The Fortune at the Bottom of the Pyramid. Strategy+business(26), 1-16. (https://bit.ly/2SDFusj) (2019-02-08).

Programa de las Naciones Unidas para el Desarrollo (PNUD). (2016). Objetivos de Desarrollo Sostenible. Recuperado de PNUD: (https://bit.ly/2cFagZg) (2019-02-05). 
Quintero, J., \& Sánchez, J. (2006). La cadena de valor: Una herramienta del pensamiento estratégico. Telos, 8(3), 377-389. (https://bit.ly/2Q9h61g) (2018-06-06).

Ribeiro, F., \& Kruglianskas, I. (2015) Principles of environmental regulatory quality: a synthesis from literature review. Journal of Cleaner Production, 96(1), 58-76. https://doi.org/10.1016/j. jclepro.2014.03.047

Ross, D., \& Rogoff, M. (2012). 'What a waste...' the World Bank's call for action. Waste Management E Research, 30(8), 755-757. https://doi.org/10.1177/0734242X12455401

Sanmartín Ramón, G. S., Zhigue Luna, R. A., \& Alaña Castillo, T. P. (2017). El reciclaje: Un nicho de innovación y emprendimiento con enfoque ambientalista. Universidad y Sociedad, 9(1), 36-40. (https://bit.ly/2N7rrFH) (2018-06-12).

Silva Naranjo, A., Morán Montalvo, C., Cárdenas Zambrano, C., Macuy Calle, J., \& Behr Gutiérrez, J. (2015). La Inflación y el ingreso de los recolectores de desechos sólidos inorgánicos reciclables de la ciudad de Guayaquil. RETOS. Revista de Ciencias de la Administración y Economía, 5(9), 73-84. https://doi.org/10.17163/ret.n9.2015.05

Sorkun, M. F. (2018). How do social norms influence recycling behavior in a collectivistic society? A case study from Turkey. Waste Management, 80, 359-370. https://doi.org/10.1016/j. wasman.2018.09.026

Sullivan Sealey, K., \& Smith, J. (2014). Recycling for small island tourism developments: Food waste composting at Sandals Emerald Bay, Exuma, Bahamas. Resources, Conservation and Recycling, 92, 25-37. https://doi.org/10.1016/j.resconrec.2014.08.008

The Economist Intelligence Unit. (2017). Avances y desafíos para el reciclaje inclusivo: Evaluación de 12 ciudades de América Latina y El Caribe. Recuperado el 8 de Junio de 2018, de Reciclaje Inclusivo: (https://bit.ly/2SNUhha) (2018-06-08).

Vázquez Morillas, A., Velasco Pérez, M., Espinosa Valdemar, R., Morales Contreras, M., Hernández Islas, S., Ordaz Guillén, M. Y., \& Almeida Filgueira, H. J. (2016). Generation, legislation and valorization of plastic waste in Latin America. Revista Internacional de Contaminacion Ambiental, 32(EspecialResiduosSolidos), 63-76. https://doi.org/10.20937/ RICA.2016.32.05.05

Velenturf, A., \& Jopson, J. (2019). Making the business case for resource recovery. Science of the Total Environment, 648, 1031-1041. https://doi.org/10.1016/j.scitotenv.2018.08.224

Vieira, V. A., \& Matheus, D. (2018). The impact of socioeconomic factors on municipal solid waste generation in São Paulo, Brazil. Waste Management and Research, 36(1), 79-85. https:// doi.org/10.1177/0734242X17744039

Wadhy Rebehy, P. P., Lucirton Costa, A., Campello, C., Espinoza, D., \& Neto, M. J. (2017). Innovative social business of selective waste collection in Brazil: Cleaner production and poverty reduction. Journal of Cleaner Production, 154, 462-473. https://doi.org/10.1016/j.jclepro.2017.03.173

Wilson, D., \& Velis, C. (2015). Waste management - still a global challenge in the 21st century: An evidence-based call for action. Waste Management and Research, 33(12), 1049-1051. https:// doi.org/10.1177/0734242X15616055

Yang, H., Huang, X., Thompson, J., \& Flower, R. (2016). Chinese landfill collapse: urban waste and human health. The Lancet Global Health, 4(7), e452. https://doi.org/10.1016/S2214109X(16)30051-1

Yang, H., Ma, M., Thompson, J., \& Flower, R. (2018). Waste management, informal recycling, environmental pollution and public health. Journal of Epidemiology and Community Health, 72(3), 237-243. https://doi.org/10.1136/jech-2016-208597 